NASA/TM-1998-208492

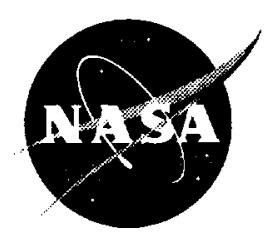

\title{
Probabilistic Modeling of Ceramic Matrix Composite Strength
}

Ashwin R. Shah

Sest, Inc., North Royalton, Ohio

Pappu L.N. Murthy

Lewis Research Center, Cleveland, Ohio

Subodh K. Mital

University of Toledo, Toledo, Ohio

Ramakrishna T. Bhatt

U.S. Army Research Laboratory, Lewis Research Center, Cleveland, Ohio

Prepared for the

39th Structures, Structural Dynamics, and Materials Conference and Exhibit cosponsored by AIAA, ASME, ASCE, AHS, and ASC

Long Beach, California, April 20-23, 1998

National Aeronautics and

Space Administration

Lewis Research Center 
Available from

NASA Center for Aerospace Information 7121 Standard Drive

Hanover, MD 21076

Price Code: A03
National Technical Information Service 5287 Port Royal Road Springfield, VA 22100 


\title{
PROBABILISTIC MODELING OF CERAMIC MATRIX COMPOSITE STRENGTH
}

\author{
Ashwin R. Shah \\ Sest, Inc. \\ North Royalton, Ohio 44133 \\ Pappu L.N. Murthy \\ National Aeronautics and Space Administration \\ Lewis Research Center \\ Cleveland. Ohio 44135 \\ Subodh K. Mital ${ }^{1}$ \\ The University of Toledo \\ Toledo, Ohio 4.3606 \\ Ramakrishna T. Bhatt \\ U.S. Army Research Laboratory \\ Lewis Research Center \\ Cleveland, Ohio 44135
}

\begin{abstract}
Uncertainties associated with the primitive random variables such as manufacturing process (processing temperature, fiber volume ratio, void volume ratio), constituent properties (fiber, matrix and interface), and geometric parameters (ply thickness, interphase thickness) have been simulated to quantify the scatter in the first matrix cracking strength (FMCS) and the ultimate tensile strength of SCS-6/RBSN (SiC fiber (SCS-6) reinforced reaction-bonded silicon nitride composite) ceramic matrix composite laminate at room temperature. Cumulative probability distribution function for the FMCS and ultimate tensile strength at room temperature $(\mathrm{RT})$ of $[0]_{8},\left[0_{2}\right]$ $\left.90_{2}\right]_{\mathrm{s}}$, and $\left[ \pm 45_{2}\right]_{\mathrm{S}}$ laminates have been simulated and the sensitivity of primitive variables to the respective strengths have been quantified. Computationally predicted scatter of the strengths for a uniaxial laminate have been compared with those from limited experimental data. Also the experimental procedure used in the tests has been described briefly. Results show a very good agreement between the computational simulation and the experimental data. Dominating failure modes in $[0]_{8},[0 / 90]_{\mathrm{s}}$ and $[ \pm 45]_{\mathrm{S}}$ laminates have been identified. Results indicate that the first matrix cracking strength for the $[0]_{8}$, and $[0 / 90]_{\mathrm{S}}$ laminates is sensitive to the thermal properties, modulus and strengths of both the fiber and matrix whereas the ultimate tensile strength is sensitive to the fiber strength and the fiber volume ratio. In the case of a $[ \pm 45]_{s}$ laminate, both the FMCS and the ultimate tensile strengths have a small scatter range and are sensitive to the fiber tensile strength as well as the fiber volume ratio.
\end{abstract}

Key words: Probability theory, simulation, probability density functions, ceramic matrix composites, sensitivity

\section{SYMBOLS}

CDF cumulative probability distribution function

CMC ceramic matrix composite

COV coefficient of variation

CTE coefficient of thermal expansion

'Resident Research Associate, NASA Lewis Research Center, Cleveland, Ohio 44135. 


$\begin{array}{ll}E_{f 11} \quad \text { fiber modulus in the longitudinal direction } & \text { matrix modulus } \\ E_{m} & \text { fiber volume ratio } \\ \text { FMCS } & \text { first matrix cracking strength } \\ S_{f 11 T} & \text { longitudinal fiber strength in tension } \\ S_{\mathrm{iS}} & \text { interphase shear strength } \\ S_{\mathrm{mS}} & \text { matrix shear strength } \\ \mathrm{S}_{\mathrm{mT}} & \text { matrix strength in tension } \\ \mathrm{t}_{\mathrm{i}} & \text { ply thickness } \\ \mathrm{VVR} & \text { void volume ratio } \\ \alpha_{\mathrm{fl1}} & \text { fiber thermal expansion coefficient in } 11 \text { direction } \\ \alpha_{\mathrm{f} 22} & \text { fiber thermal expansion coefficient in } 22 \text { direction } \\ \alpha_{\mathrm{m}} & \text { matrix thermal expansion coefficient }\end{array}$

INTRODUCTION

Aircraft engine propulsion system components are subject to a complex state of thermomechanical loading cycles in an aggressive combustion environment. Owing to their oxidation resistance, strength and microstructural stability. silicon carbide fiber-reinforced silicon-based ceramic matrix composites are prime candidate materials for high temperature components such as combustor liners, nozzle vanes, and blades.

Ceramic matrix composites (CMC) are heterogeneous brittle materials consisting of fibers, matrix, and coating/interphase, and are fabricated by novel fabrication approaches. Although these materials exhibit a considerable scatter in their mechanical and thermal properties due to inherent variations in the constituent (fiber, matrix and interphase) properties and geometric parameters at ply and laminate levels, these materials are of interest to designers because of their near net shape fabricability and high tou ghness. Designing structural components made of CMCs with specified reliability is a complex task. Conventional deterministic design methodology accounts for uncertainties using safety factors or load factors which are at times overly conservative. Therefore, there is a need to develop probabilistic models to predict scatter in the thermomechanic al properties and the composite strengths required to design CMC components.

A formal methodology has been developed by Murthy et al. 1] to quantify probabilistic mechanical and thermal properties, and behavior of CMC. This methodology has been incorporated into a computer code called Probabilistic CEramic Matrix Composite ANalyzer (PCEMCAN) [2] The code can compute the cumulative probability distribution function (CDF) of the composite properties, and quantify their sensitivity to the primitive random variables. The primitive random variables participate at the lowest level (e.g. the micromechanics level) in defining a global composite property. Typical examples of primitive r. ndom variables are fiber, matrix and interphase properties, fiber volume ratio, ply thickness, etc.

The probabilistic simulation approach can also be used as a design tool to reduce material development costs in optimizing composite properties. Furthermore, the reliability of designed structural elements can be 
predicted readily. The validity and utility of new approaches, however, need to be properly established through comparison with the experimental data.

The objective of the current research effort is to use the probabilistic simulation approach to predict the observed scatter in the first matrix cracking strength (FMCS) and ultimate tensile strength at room temperature for the three SCS-6/RBSN (SiC fiber reinforced reaction-bonded silicon nitride composite) laminates, namely $[0]_{8},\left[0_{2}\right.$ ' $\left.90_{2}\right]_{\mathrm{s}}$, and $\left[ \pm 45_{2}\right]_{\mathrm{s}}$, and to compare the predicted results with the experimental data. The first matrix cracking strength is generally used to determine the design allowable whereas the ultimate strength provides an idea of the margin of safety. The simulation process includes uncertainties in the constituent properties, fabrication process variables, and the stress free temperature (process) to account for any residual stresses. Initially the methodology has been calibrated by comparing the simulation results with the experimental data for a uniaxial laminate. The residual stresses arising out of the fabrication process temperature affect the strength of a composite laminate. Therefore, the importance of fabrication process temperature will be highlighted. Also, the failure mode for a given laminate configuration determines the first matrix cracking strength and ultimate strength. Hence, the significance of failure mode from a reliability viewpoint will be elucidated in the paper. It is important to realize that the availability of enough experimental data for different laminate configurations for the purpose of probabilistic verification is difficult. The probabilistic/deterministic results were compared with experimental data for $[0]_{8}$ laminate, and for the remaining laminates only deterministic behavior was compared due to lack of experimental data for a full probabilistic description of the behavior.

\section{EXPERIMENTAL PROCEDURE}

\section{Composite Fabrication}

The starting materials for the SiC/RBSN composites were SiC fibers and silicon powder. The $142 \mu \mathrm{m}$ diameter $\mathrm{SiC}$ fiber used was obtained from Textron Specialty Materials, Lowell Massachusetts. This SiC fiber, designated as double coated SCS- 6 by the manufacturer, contained a mixture of SiC/C on its outer surface. The silicon powder is procured from Union Carbide, Linde Division, Tonawanda, New York. The SiC/RBSN composites were produced by a two step process. In the first step, the fiber mats and silicon tapes were hot pressed to prepare preforms. In the second step the preforms were nitrided to convert silicon to silicon nitride matrix. Salient features of the composite fabrication are given here, but detailed account of fabrication is reported elsewhere [3].

For the fiber mats, the SCS-6 fibers were wound on a cylindrical drum and coated with a solution of a fugitive polymer binder in an organic solvent. After carefully drying, the fiber mats of required dimensions were cut. For the preparation of silicon powder cloth, silicon powder, an additive (for enhancing nitridation), a fugitive polymer binder, and an organic solvent were mixed in a high speed blender until a dough was formed. The dough was rolled to the desired thickness and cut to required dimensions. For the composite preform fabrication, alternate layers of $\mathrm{SiC}$ fiber mat and silicon cloth, were stacked in a molybdenum die and hot pressed in vacuum or in a nitrogen environment at a suitable combination of temperature and pressure to produce a SiC/Si preforms.

The SiC/Si preforms were then transferred to a horizontal nitridation furnace consisting of a recrystallized $\mathrm{Al}_{2} \mathrm{O}_{3}$ reaction tube with stainless steel end caps. The high purity nitrogen gas was flowed through the furnace before, during and after nitridation. Nitridation of the composite was performed between 1200 and $1400^{\circ} \mathrm{C}$. The nitrided composite panel, was ground on emery paper to remove any loose surface $\mathrm{Si}_{3} \mathrm{~N}_{4}$ particles. Typical dimensions of the nitrided panels were $125 \times 50 \times 1.2 \mathrm{~mm}$. Using the above fabrication methodology $[0]_{8},\left[0_{2} / 90_{2}\right]_{\mathrm{s}}$, and $\left[ \pm 45_{2}\right]_{\mathrm{s}}$ laminates were prepared.

\section{Specimen Preparation and Testing}

Tensile specimens of dimensions $150 \times 12.7 \times 1.2 \mathrm{~mm}$ were prepared by cutting and grinding the composite panels with a diamond impregnated abrasive wheel. A pair of glass fiber reinforced epoxy tabs of dimensions $38 \times 12.7 \times 1 \mathrm{~mm}$ were adhesively bonded at the specimen ends leaving $25 \mathrm{~mm}$ as the test gage length. A wire wound 
strain gage was adhesively bonded to the specimen gage section to monitor the axial and transverse strains. The tensile tests were performed in an Instron machine at a cross-head speed of $1.26 \mathrm{~mm} / \mathrm{min}$.

\section{PROBABILISTIC STRENGTH SIMULATION METHODOLOGY}

The research described in this paper focuses on two major issues: (1) the quantification of scatter in the CMC laminate strength and, (2) the comparison of computationally simulated results with the experimental data.

(I) Quantification of scatter in the CMC laminate strength methodology.-The approach developed by Murthy et al. [1] has been used to simulate the probabilistic strength and quantify uncertainties in CMC laminates. This methodology uses the fast probability integration technique (FPI) developed under a NASA Lewis Research Center sponsored program [4]. The procedure involves the following steps as depicted in Fig. 1.

(1) Identify the independent uncorrelated input variables and their probability distributions. Examples of independent variables are constituent properties. fiber volume ratio, void-volume ratio (VVR), ply thickness, ply alignment, fiber and matrix strengths, etc.

(2) Develop a function (called the performance/response function) that defines a relationship between a response variable (first matrix cracking strength, ultimate strength, modulus are typical response variables for $\mathrm{CMCs}$ ) and the independent variables. A perturbation analysis approach is used to develop the performance function. Perturbation analysis involves performing several deterministic analyses for different magnitudes of selective samples of primitive random variables using the micro/macromechanics theory included in PCEMCAN [2]. The procedure for computing deterministic strength is described in the paragraphs below. Responses obtained from these analyses are used to generate a response surface required by FPI for the prohabilistic assessment of the response.

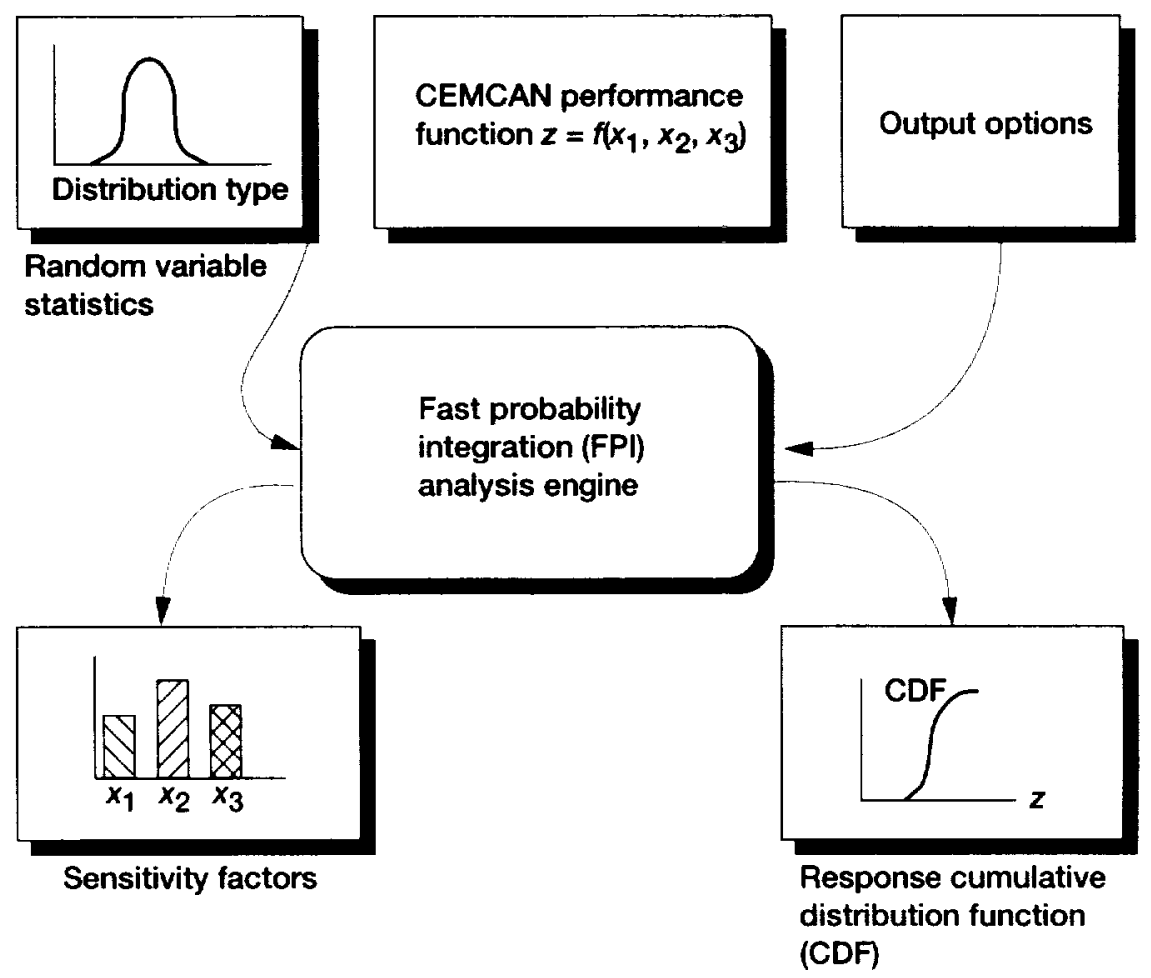

Figure 1.-Fast probability integration input-output schematic. 
(3) Use the FPI technique to compute the cumulative probability distribution function of the response and its sensitivity to the primitive random variables.

Deterministic strength computation procedure.-It is worth recording the procedure, assumptions and underlying concepts used in the perturbation analysis to determine the FMCS and the ultimate strength. A unique capability available in PCEMCAN computer code [2] to carry out progressive fracture analysis with microstress redistribution at every incremental load step has been used to determine these strengths (refer to Fig. 2 for the schematic description of the integrated approach being discussed here). Every ply in a laminate is divided into smaller slices of a reasonable size specified by the user. At every load increment, the microstresses in all the constituents of every slice of every ply are computed and compared against their respective current strengths. A maximum stress criterion is used for the failure analysis, meaning a constituent has failed if its stress exceeds its preset strength value. In case of a failure, the modulus of the failed constituent is set to a negligible value for the subsequent analysis. A slice is assumed to have failed under the longitudinal loading when a fiber has failed. A slice is assumed to have failed under transverse/shear loading, if matrix/interphase has failed. Thus, in the next step, the load carried by the failed slice is redistributed to the remaining slices. The load that was carried by the failed slice is then added appropriately to the laminate load and the laminate analysis is performed again. The process is repeated until the equilibrium (convergence) between the applied load and a damage state is reached for a given load step. Convergence is established when the mid plane strains, ply strains and slice strains are within 5 percent of those in the previous iteration. The nonlinearity observed in the stress-strain behavior arises primarily due to the stress redistribution.

The FMCS is the stress at which the matrix starts failing. In the current analysis, a first ply matrix failure criteria is used to determine the FMCS. It means that the FMCS is reached when the matrix in all the slices of any ply have failed. Basically at this point the stress-strain curve starts changing slope since the load is mainly carried by the fibers in each ply then after. Even after the FMCS is reached, the analysis is continued to assess the ultimate strength since the plies that have not failed completely (including fibers) can still carry load. An incremental load is applied until all the plies in laminate fail completely and can no longer carry further load. At this point, the laminate is assumed to have reached the ultimate strength.

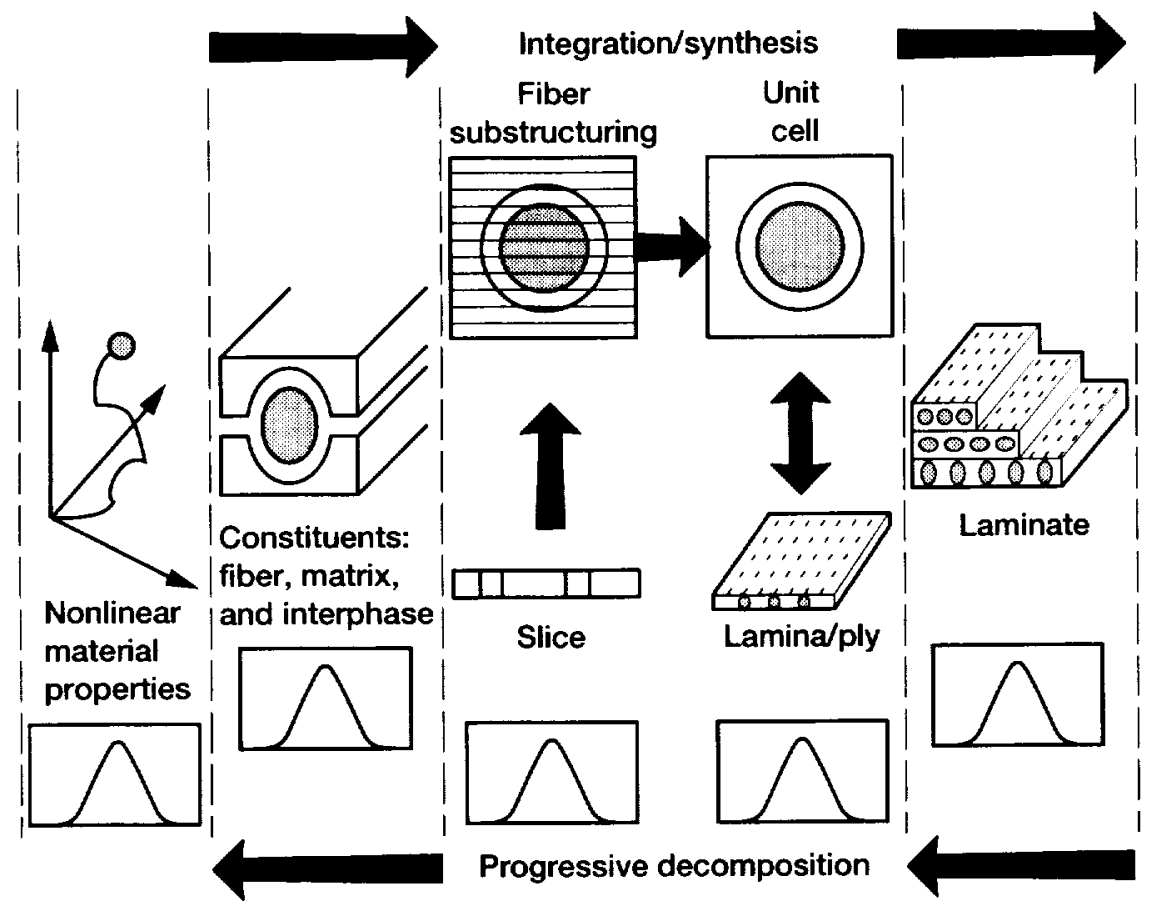

Figure 2.-Integrated probabilistic ceramic matrix composite mechanics approach. 


\section{RESULTS AND DISCUSSION}

\section{Tensile Behavior of laminates}

The room temperature tensile stress-strain behavior of the uniaxial and cross-ply SCS-6/RBSN laminates are shown in Figs. 3 to 5. The tensile stress-strain curve show three distinct regions: an initial linear elastic region, a very short nonlinear region, and a second linear region. The nonlinear signifies the start of the matrix cracking to saturation when the entire load is carried only by fibers. The stress corresponding to the deviation from the initial linearity in the stress-strain curve is considered to be the first matrix cracking stress (FMCS). Indeed, at this stress level, previous optical microscopy and in-situ $x$-ray studies $[5,6]$ confirmed formation of a through-the-thickness matrix crack. From the tensile stress-strain curves, the primary elastic modulus, first matrix cracking stress and strain, and ultimate tensile strength and strain were noted. The room temperature tensile property data for the three laminates are summarized in Table I. The data represent an average of 60 specimens of $[0]_{8}$ laminates, and 10 specimens of $\left[0_{2} /\right.$ $90_{2} I_{s}$, and 5 specimens of $\left[ \pm 45_{2}\right]_{s}$.

The comparison of the experimental data with the deterministic computational simulation results is depicted in Figs. 3 to 5 and details of the verification procedure are given in Ref. 7 . It is seen from these figures that the computational results compare fairly well with the experimental data.

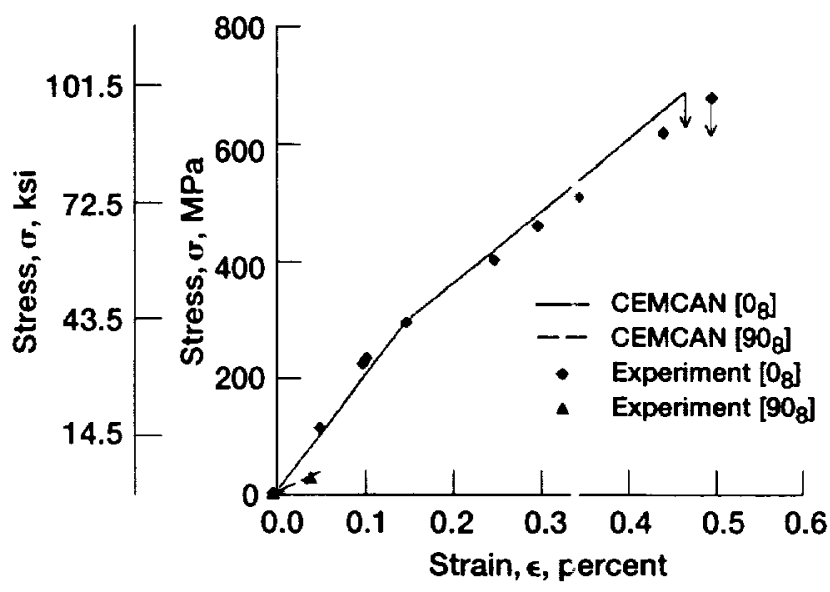

Figure 3.-Room-temperature stress-strain curves to failure of $[0]_{8}$ and $[90]_{8} \mathrm{SiC} / \mathrm{RBSN}$ composite.

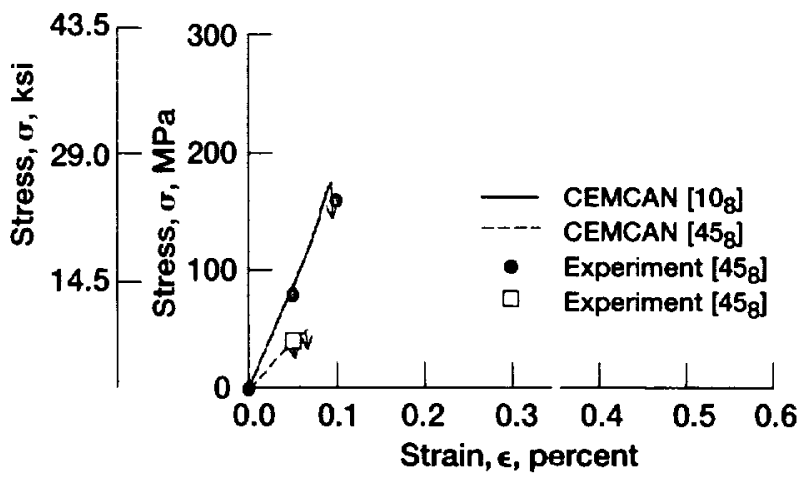

Figure 4.-Room-temperature stress-strain curves to failure of $[10]_{8}$ and $[45]_{8}$ laminates of SiC/RBSN. 


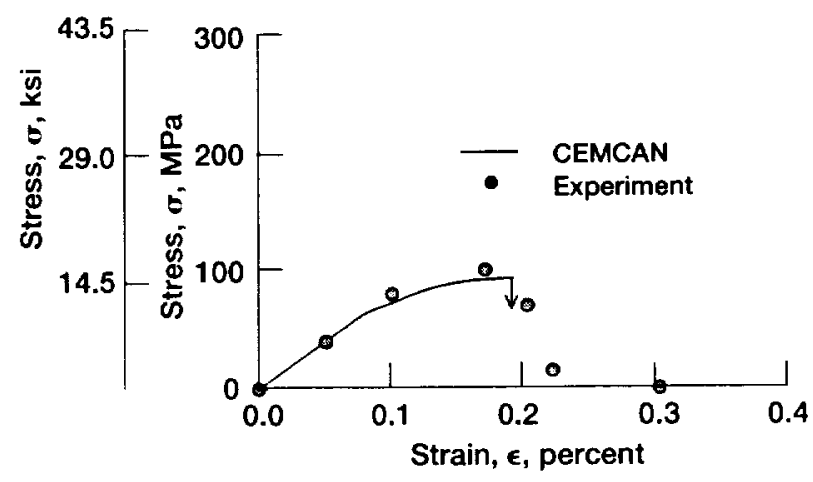

Figure 5.-Room-temperature stress-strain curves to failure of $\left[ \pm 45_{2}\right]_{s}$ SiC/RBSN laminate.

TABLE I-_-PRIMITIVE RANDOM VARIABLES DISTRIBUTION PARAMETERS

\begin{tabular}{|l|c|c|c|c|}
\hline \multicolumn{1}{|c|}{ Variable } & Units & $\begin{array}{c}\text { Mean } \\
\text { value }\end{array}$ & $\begin{array}{c}\text { Cofficient } \\
\text { of variation }\end{array}$ & $\begin{array}{c}\text { Distribution } \\
\text { type }\end{array}$ \\
\hline \multicolumn{5}{|c|}{$\mathrm{SCS}-6$ fiber } \\
\hline Modulus. $\mathrm{E}_{\mathrm{f} 11}$ & $\mathrm{GPa}$ & 390 & 0.55 & Lognormal \\
\hline $\begin{array}{l}\text { Coefficient of thermal } \\
\text { expansion. } \alpha_{\mathrm{m}}\end{array}$ & $\mathrm{ppm} /{ }^{\circ} \mathrm{C}$ & 4.1 & 0.07 & Normal \\
\hline $\begin{array}{l}\text { Longitudinal strength } \\
\text { in tension. } \mathrm{S}_{\mathrm{fl1}}\end{array}$ & $\mathrm{GPa}$ & 2.86 & 0.04 & Weibull \\
\hline \multicolumn{5}{|c|}{$\mathrm{RBSN}$ matrix } \\
\hline Modulus. $\mathrm{E}_{\mathrm{m}}$ & $\mathrm{GPa}$ & 110 & 14 & Weibull \\
\hline $\begin{array}{l}\text { Coefficient of thermal } \\
\text { expansion, } \alpha_{\mathrm{m}}\end{array}$ & $\mathrm{ppm} /{ }^{\circ} \mathrm{C}$ & 2.2 & 0.06 & Normal \\
\hline Shear strength. $\mathrm{S}_{\mathrm{m} s} \mathrm{MPa}$ & 55 & 0.34 & Weibull \\
\hline Strength in tension $\mathrm{S}_{\mathrm{ml}}$ & $\mathrm{MPa}$ & 84 & 26 & Weibull \\
\hline \multicolumn{5}{|c|}{ Carbon interphase } \\
\hline Shear strength, $\mathrm{S}_{\mathrm{is}}$ & $\mathrm{MPa}$ & 55 & 0.34 & Weibull \\
\hline Thickness. $\mathrm{t}_{\mathrm{i}}$ & $\mu \mathrm{m}$ & 2.5 & 0.25 & Weibull \\
\hline \multicolumn{5}{|c|}{ Process variable } \\
\hline Fiber volume ratio & ---- & 0.29 & 0.05 & Normal \\
\hline
\end{tabular}

\section{Probabilistic Strength Prediction and Verification}

Computational simulation of probabilistic strength has been performed using the PCEMCAN code for $[0]_{8}$. $[0 / 90]_{2}$, and $\left[ \pm 45_{2}\right]_{\mathrm{S}}$ SCS-6/RBSN laminates. The mean values, coefficient of variation and the distribution types of the primitive random variables related to the fiber, matrix, and interphase properties, fiber volume ratio (FVR) and the ply thickness used in the analysis for the $[0]_{8}$ laminate are shown in Table $\mathrm{I}$. The values used for the $\left[0_{2} / 90_{2}\right]_{\mathrm{S}}$ and $\left[ \pm 45_{2}\right]_{\mathrm{s}}$ laminates are the same as those in Table I except that the mean FVR is 0.36 . The distribution types and magnitude of scatter in these primitive random variables have been assumed based on the engineering judgment and past experience. There were many more variables associated with the fiber, matrix and interphase properties which were considered as random in the analysis. However, the variables that were found to have an insignificant effect on the probabilistic strengths have been omitted from the list for the sake of brevity.

Additionally, the strength simulation accounts for any residual stresses that arise from the fabrication of these composites. It has been assumed in the present simulation that very little degradation (maximum 10\%) of the constituent properties such as modulus, etc. with respect to the room temperature properties occur within the processing and maximum use temperature range. Also, the constituents are assumed to be homogeneous, and isotropic in this work. The importance of process temperature has been highlighted by the sensitivity computations 
for the strengths. Detailed description of the results for each laminate configuration is given in the subsequent paragraphs.

(i) Uniaxial, $[0]_{8}$ laminate.-The first matrix cracking and ultimate strength of a uniaxial laminate have been simulated using PCEMCAN code. A stress free temperature of $540^{\circ} \mathrm{C}$ was assumed in the analysis. The thermal processing and the mechanical loads were applied incrementally. A reasonably small size load step was used in the analysis to determine failure modes and a more accurate failure strength of constituents. At every load step, the stresses and strains in the constituent were observed with respect to the failure criteria to determine failure strengths.

The CDF for the computed FMCS and that obtained from the experimental data are plotted in Fig. 6 . The experimental test data CDF was obtained using 60 test samples. The computationally obtained mean first matrix cracking strength is $225 \mathrm{MPa}$ that matches with $221 \mathrm{MPa}$ from the test data. The coefficient of variation (COV) for the FMCS is about 11.34 percent. The predicted probabilistic scatter in the FMCS range from 124 to $303 \mathrm{MPa}$ as compared to 172 to $276 \mathrm{MPa}$ obtained experimentally. The experimentally observed scatter based on 60 samples fall within the predicted scatter.

Sensitivity of the FMCS to the primitive random variables are plotted in Fig. 7. It is seen that the FMCS is sensitive (in the descending order) to the thermal expansion coefficient (CTE) of the fiber ( $\alpha_{\mathrm{f} 11}$,), longitudinal fiber modulus $\left(E_{\mathrm{f} 11}\right)$, matrix strength in tension $\left(\mathrm{S}_{\mathrm{mT}}\right)$, fiber volume ratio (FVR), matrix thermal expansion coefficient $\left(\alpha_{m}\right)$, and matrix modulus $\left(E_{m}\right)$. In a composite in which the modulus and CTE of the fiber are greater than those of the matrix. compressive residual stresses are generated in the matrix after cooling the composite from the fabrication temperature. In this case the compressive residual stress in the matrix increases the FMCS. In contrast, in a composite in which the modulus and CTE of the fiber are lower than those of the matrix, tensile residual stresses are generated. This will decrease the FMCS. Therefore, the thermal residual stresses significantly affect FMCS in composites. Thus, the processing temperature plays an important role in affecting the design strength. Also, to obtain a reduced scatter in the design strength, the uncertainty in these variables should be controlled. Furthermore, processing techniques to reduce the residual stresses should be developed. Note that the stress free temperature is considered deterministic in the current analysis.

Figure 8 depicts the comparison of probabilistic and experimental CDF of the ultimate strengths. The predicted mean of $658 \mathrm{MPa}$ compares closely with the experimentally obtained mean of $690 \mathrm{MPa}$ and COV is

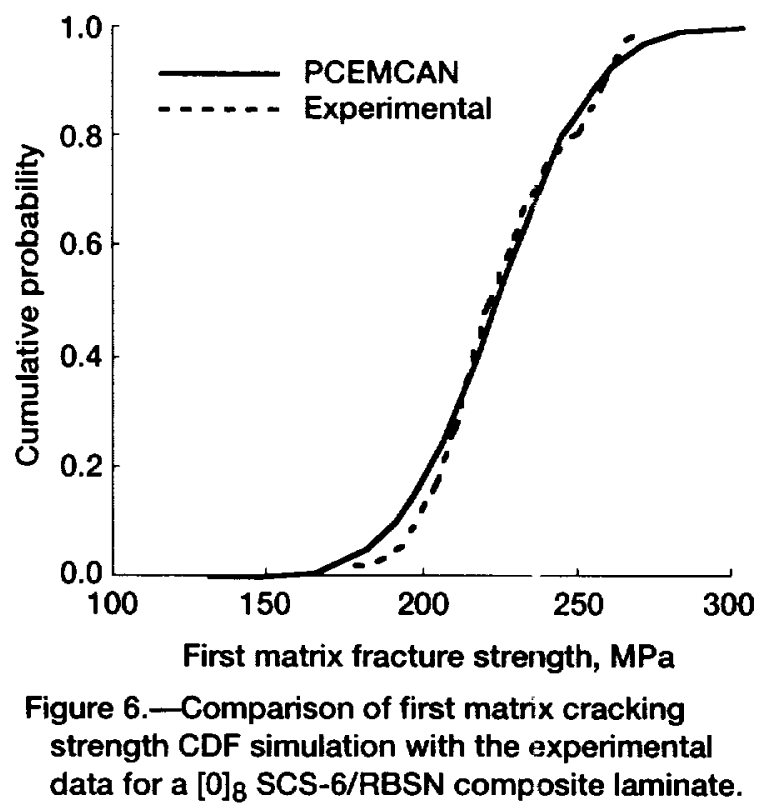




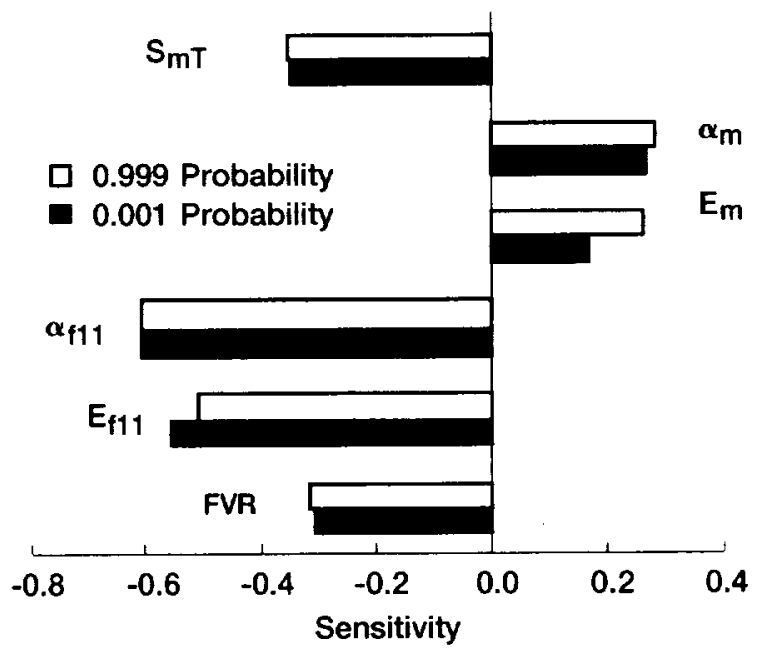

Figure 7.-Sensitivity of the first matrix cracking strength to the primitive random variables of a $[0]_{8}$ SCS-6/RBSN composite laminate.

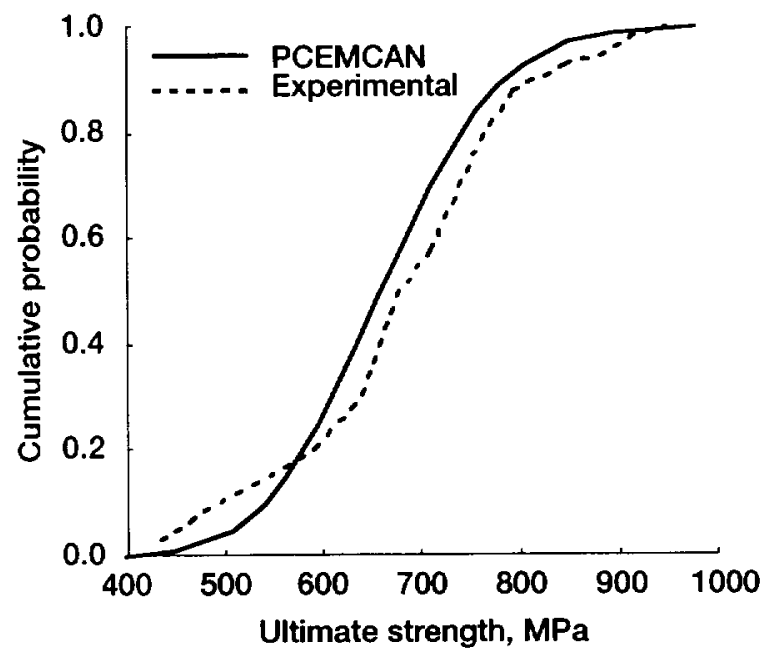

Figure 8.-Comparison of ultimate strength CDF simulation with the experimental data for a $\left.{ }^{[0}\right]_{8}$ SCS-6/RBSN composite laminate.

14.8 percent. The predicted scatter is from 345 to $966 \mathrm{MPa}$ as compared to that of 414 to $966 \mathrm{MPa}$ obtained experimentally. Looking at the overall CDF curves, the ultimate strength CDF and scatter are in good agreement.

The sensitivity of ultimate strength to the primitive random variables is shown in Fig. 9 and is mainly controlled by the longitudinal tensile strength of the fiber $\left(S_{f 11 T}\right)$ and the fiber volume ratio. Thus, the ultimate strength is mainly controlled by the fibers as expected. This is due to the fact that after the matrix starts cracking and becomes saturated with cracks, thereafter the load is mainly carried by the fibers. Since the fiber tensile strength is the only variable that controls the ultimate strength, the COV of the predicted ultimate strength is almost the same as that of the fiber tensile strength. It is worth noting here that the reliable margin of safety for the uniaxial laminates is fairly large and the fiber properties play a major role for the FMCS as well as ultimate strength. 


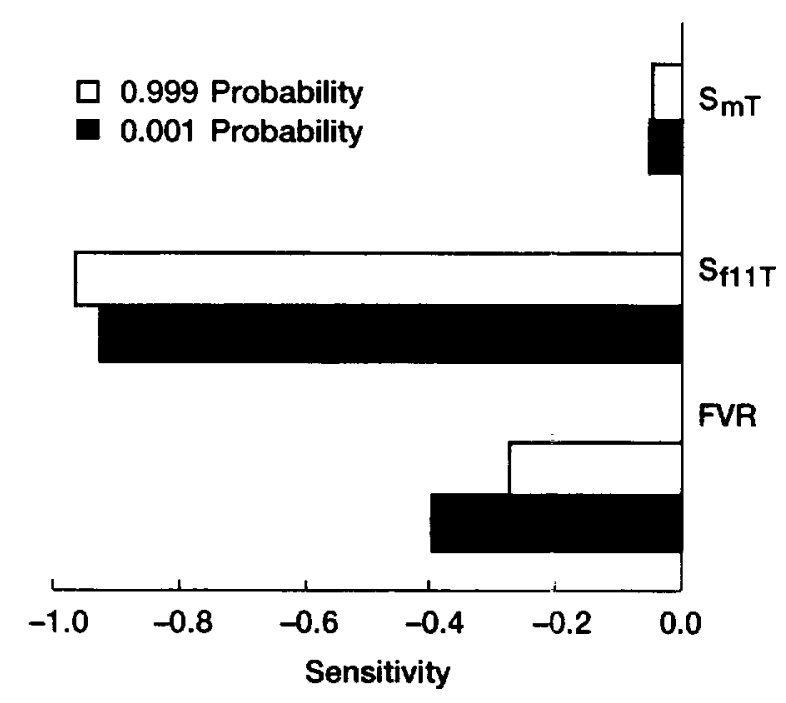

Figure 9.-Sensitivity of the ultimate strength to the primitive random variables of a $[0]_{8} \mathrm{SCS}-6 / \mathrm{RBSN}$ composite laminate.

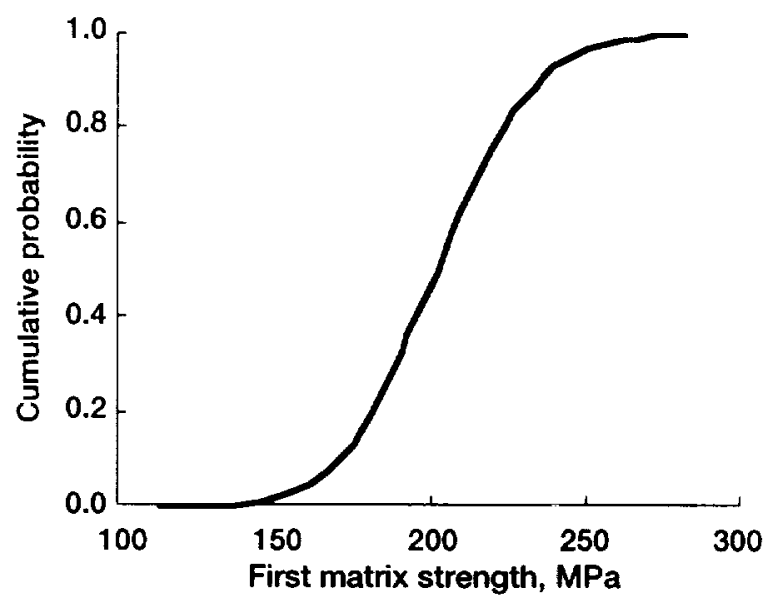

Figure 10.-Cumulative probability distribution function of the first matrix cracking strength of a $\left[\mathrm{O}_{2} / 90_{2}\right]_{2}$ SCS-6/RBSN composite laminate.

(ii) Cross-ply, 10,190, laminate configuration. - Probabilistic tensile strength of a cross ply laminate has been computed using the PCEMCAN computer code and the approach discussed earlier. The deterministic verification for this laminate has been performed in Ref. 7. Using the same properties and a stress free temperature given in Ref. 7 and listed here in Table I, the CDFs of the first matrix strength and the ultimate strength were determined. The CDF of the FMCS and its sensitivity to the primitive random variables are plotted in Figs. 10 and 11, respectively. The mean FMCS is $204 \mathrm{MPa}$ and its coefficient of viriation (COV) is 12.3 percent. It is worth noting here that the FMCS and its COV are not much different from $t$ e uniaxial case. The scatter range is from 112 to $282 \mathrm{MPa}$. Also, along the same line the primitive variables that control the first matrix strength are the same as that for the uniaxial strength, and in the same order of importance. The important variables are $\alpha_{\mathrm{f} 11}, \mathrm{E}_{\mathrm{f} 11}, \mathrm{~S}_{\mathrm{mT}}, \mathrm{FVR}$, $\alpha_{\mathrm{m}}, \mathrm{E}_{\mathrm{m}}$, and $\alpha_{\mathrm{f} 22}$. Once again the stress free temperature controls the design strength, i.e., FMCS for the reasons discussed above. 


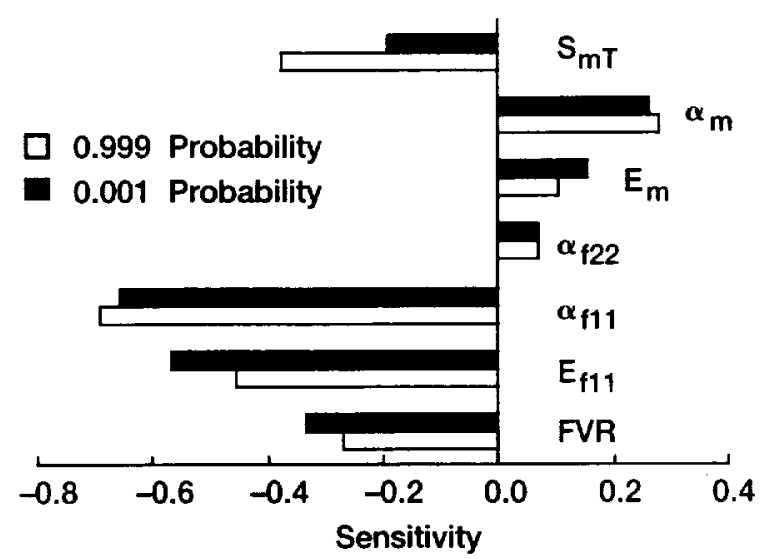

Figure 11.-Sensitivity of the first matrix cracking strength to the primitive random variables of a $\left[0_{2} / 90_{2}\right]_{s}$ SCS-6/RBSN composite laminate.

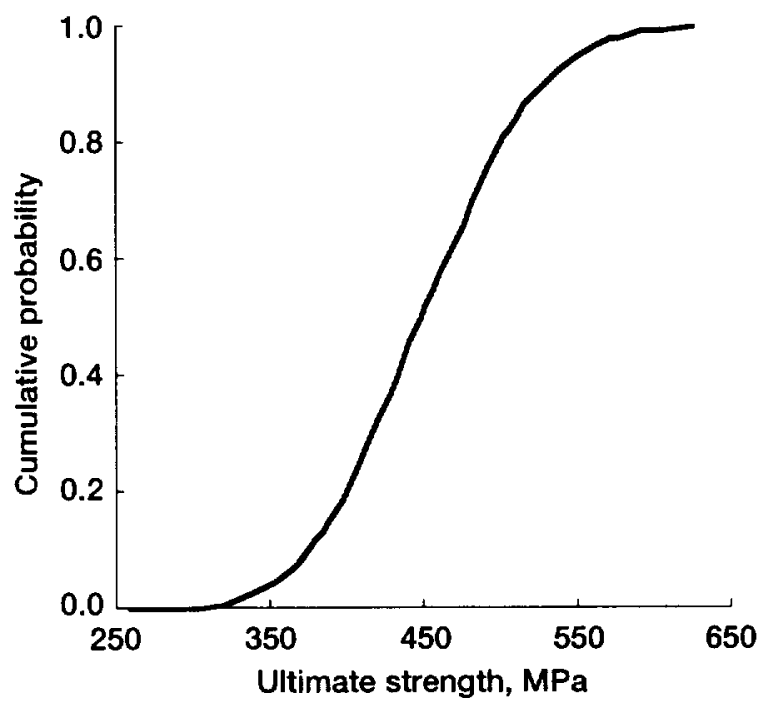

Figure 12.-Cumulative probability distribution function of the ultimate strength of a $\left[\mathrm{O}_{2} / \mathrm{SO}_{2}\right]_{\mathrm{s}}$ SCS-6/RBSN composite laminate.

The ultimate strength CDF range from 257 to $626 \mathrm{MPa}$ as shown in Fig. 12 with a mean strength of $446 \mathrm{MPa}$ and COV being 13.56 percent. The scatter range and the mean strength have reduced noticeably due to the fact that less amount of fiber is available in the load direction and it is mainly governed by the $S_{f 11 T}$ and FVR as shown in Fig. 13. Also, after the matrix is saturated with cracks the load is mainly carried by the $\left(0^{\circ}\right.$ plies only. At low cumulative probability levels the importance of both of these variables is the same. However, at higher cumulative probability level, the $S_{f 11 T}$ dominates due to the larger magnitude of strength. The low probability levels are important from the reliability point of view. Therefore, it can be said that the probabilistic behavioral pattern is similar for uniaxial and cross-ply laminates.

(iii) $\left[ \pm 45_{2}\right]_{s}$ Laminate configuration. - The constituent properties and the probabilistic data for this laminate configuration is the same as that for the $\left[0_{2} / 90_{2}\right]_{s}$ configuration. The CDF of the first matrix cracking strength and the ultimate strength for this configuration are plotted in Fig. 14 and their sensitivity to the primitive random variables are depicted in Fig. 15. It is important to note in this case that the FMCS and the ultimate strengths turn out to be the same. This is mainly due to the fact that the failure of laminate occurs due to the normal and shear failure of the matrix/interphase as evidenced by the sensitivity data in Fig. 15. This is the characteristic of a shear failure 


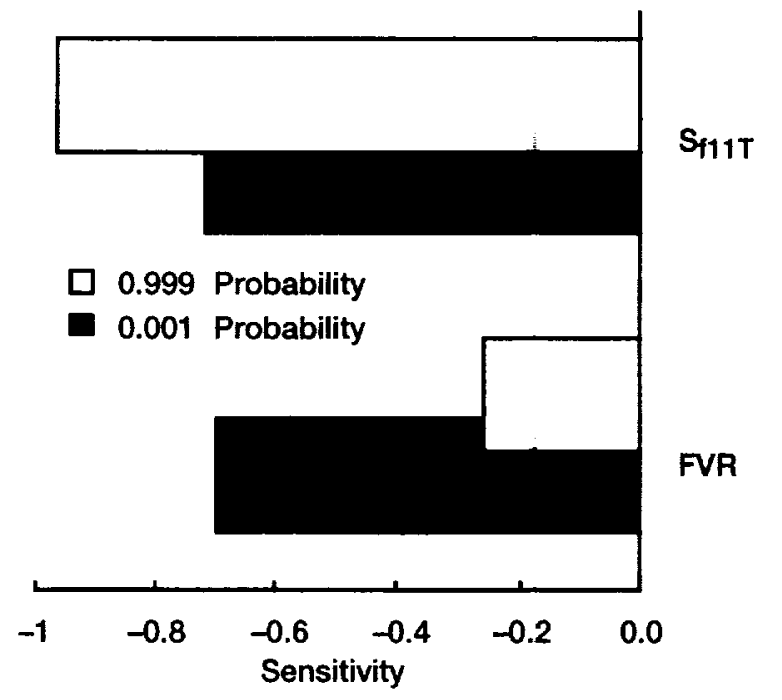

Figure 13.-Sensitivity of the ultimate strength to the primitive random variables of a $\left[\mathrm{O}_{2} / 9 \mathrm{O}_{2}\right]_{\mathrm{s}}$ SCS-6/RBSN composite laminate.

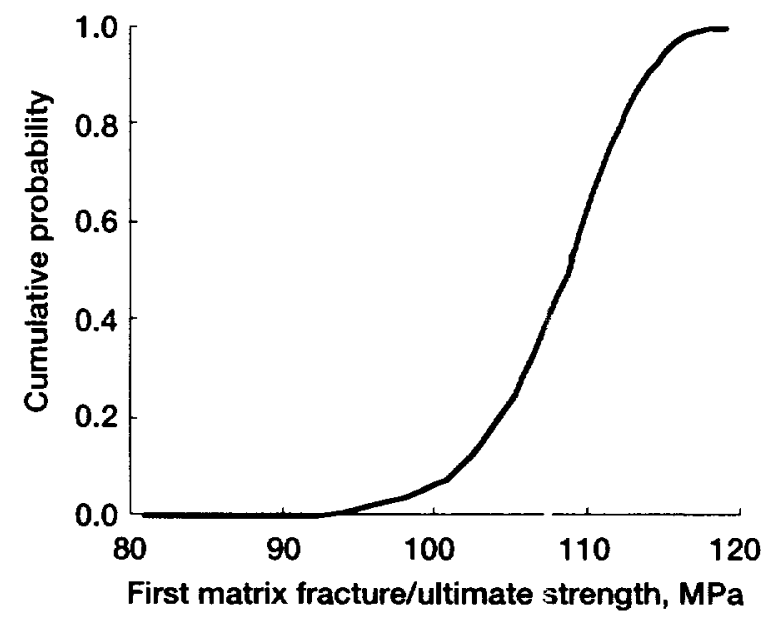

Figure 14.-Cumulative probability distribution function of the first matrix cracking/ultimate strength of a $[45 /-45]_{s}$ SCS-6/RBSN composite laminate.

mode. These failure modes have been confirmed by the optical micro icopic observations of the failed specimens [5]. Also, the deterministic strength verification of this laminate configur: tion has been performed in Ref. 7 and depicted in Fig. 5. The mean first matrix cracking and ultimate failure strength is $108 \mathrm{MPa}$ and the COV is 4.7 percent. The range of the scatter is from 81 to $119 \mathrm{MPa}$ which is a very small rang : as expected for shear mode failures. Also, the failure strength is sensitive to the matrix and interphase shear strengthis and mostly dominated by the matrix at all probability levels. It is important to note here that controlling the scatter in matrix and interphase shear strengths may not control the scatter of the failure strength due to the fact that the shear failures are sudden in nature as evidenced by a very small scatter range.

\section{SUMMARY AND CONCLLSIONS}

A methodology to quantify scatter in the first matrix cracking strength and the ultimate strength of the SCS-6/RBSN composite laminates has been developed and the predictions are compared with the limited 


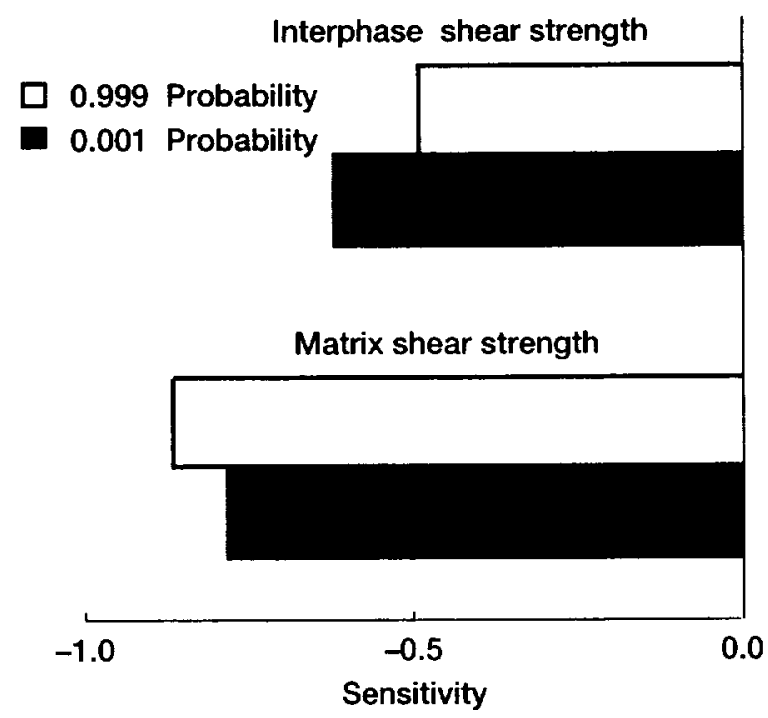

Figure 15.-Sensitivity of the first matrix cracking' ultimate strength to the primitive random variables of a $\left[ \pm 45_{2}\right]_{s}$ SCS-6/RBSN composite laminate

experimental data. The experimental results for unidirectional laminates agreed well with the computationally predicted probabilistic strengths. Two more laminate configurations, $\left[0_{2} / 90_{2}\right]_{s}$, and $\left[ \pm 45_{2}\right]_{s}$, have also been studied, however, due to the lack of sufficient data, the probabilistic simulations could not be verified. The deterministic results did agree well with the experimental results. Collectively, the results provide a valuable insight to material developers and design engineers. The material developers can utilize the sensitivity information to produce a better material with lesser scatter. Also, the design engineer can use the probabilistic strength information to quantify the conservatism in the design and reliability of the component. Based on the results it has been observed that the scatter in the strengths and their sensitivity to the random variables is controlled by the dominating failure modes and stress free temperature. In cases when the failure is governed by the normal tension failure in the matrix, the thermal properties of the fiber and matrix, fiber and matrix modulus, matrix strength in tension and FVR controls the first matrix cracking strength. Therefore, the design strength scatter can be improved by controlling the variables that affect the composite manufacturing process. On the other hand, the scatter in the reliable safety margin can be reduced by controlling the scatter in the fiber tensile strength and the fiber volume ratio.

\section{REFERENCES}

1. Murthy, P.L.N., Mital, S.K. and Shah, A.R.: Probabilistic Micromechanics and Macromechanics for Ceramic Matrix Composites, NASA TM-4766, June 1997.

2. Shah, A.R., Mital, S.K. and Murthy, P.L.N.: “PCEMCAN (Probabilistic Ceramic Matrix Composite Analyzer) User's Guide Version 1.0, NASA TM-206984, 1998.

3. Bhatt, R.T.: "Method of Preparing Fiber Reinforced Ceramic Materials," U.S. Pat. No. 4689188, 1987.

4. Probabilistic Structural Analysis Methods for Select Propulsion Components, Annual Reports 1-6, NASA Contract NAS3-24389, 1985-1990, Southwest Research Institute, San Antonio, TX.

5. Bhatt, R.T. and Philips, R.E.: "Laminate Behavior for SiC Fiber-Reinforced Reaction Bonded Nitride Matrix Composites," NASA TM-101350, 1988.

6. Baaklini, G.Y. and Bhatt, R.T.: "In-Situ X-Ray Monitoring of Damage Accumulation in SiC/RBSN Tensile Specimens," Ceram. Eng. Sci. Proc. 12, (7-8), 1599, 1991.

7. Mital, S.K. Murthy, P.L.N. and Chamis, C.C.: Modelling of Stress/Strain Behavior of Fiber Reinforced Ceramic Matrix Composites Including Stress Redistribution, NASA TM-106789, Dec. 1994. 
Public reporting burden for this collection of intormation is estimated to average 1 hour per response, includ mg the time for reviewing instructions, searching existing data sources, gathering and maintaining the data needed, and completing and reviewing the collection of information. Serid comments regarding this burden estimate or any other aspect of this collection of intormation, including suggestions for reducing this burden, to Washington Headquaners Services, Directorate for Information Operations and Reports, 1215 Jefferson Davis Highway, Suite 1204. Arlington, VA 22202-4302, and to the Office of Management and Budget. Pape work Reduction Project (0704-0188). Washington, DC 20503.

\begin{tabular}{l|l|l}
\hline 1. AGENCY USE ONLY (Leave blank) & 2. REPORT DATE & 3. REFORT TYPE AND DATES COVERED
\end{tabular}

\section{TITLE AND SUBTITLE}

September 1998

Technical Memorandum

Probabilistic Modeling of Ceramic Matrix Composite Strength

6. AUTHOR(S)

WU $-523-21-13-00$

Ashwin R. Shah. Pappu L.N. Murthy, Subodh K. Mital, and Ramakrishna T. Bhatt

7. PERFORMING ORganization NAME(S) AND ADDRESS(ES)

National Aeronautics and Space Administration

Lewis Research Center

Cleveland, Ohio $44135-3191$

5. FUNDING NUMBERS

9. SPONSORING/MONITORING AGENCY NAME(S) AND ADDRESS(ES)

National Aeronautics and Space Administration

Washington. DC 20546-0001

8. PERFORMING ORGANIZATION REPORT NUMBER

$\mathrm{E}-11281$

10. SPONSORING/MONITORING AGENCY REPORT NUMBER

NASA TM-1998-208492

\section{SUPPLEMENTARY NOTES}

Prepared for the 39th Structures, Structural Dynamics, and Materials Conference and Exhibit cosponsored by AIAA, ASME, ASCE, AHS, and ASC, Long Beach, California, April 20-23, 1998. Ashwin R. Shah, Sest, Inc., North Royalton, Ohio 44133; Pappu L.N. Murthy, Lewis Research Center; Subodh K. Mital, University of Toledo, Toledo, Ohio 43606; and Ramakrishna T. Bhatt, U.S. Army Research Laboratory, Lewis Research Center, Cleveland, Ohio. Responsible person, Pappu L.N. Murthy, organization code 5910, (216) 43.3-3332.

12a. OISTRIBUTION/AVAILABILITY STATEMENT

Unclassified - Unlimited

Subject Category: 24

Distribution: Nonstandard

This publication is available from the NASA Center for AeroSpace Information, (301) $621-0390$.

13. ABSTRACT (Maximum 200 words)

Uncertainties associated with the primitive random variables such as man ifacturing process (processing temperature. fiber volume ratio, void volume ratio), constituent properties (fiber, matrix and interface), and geometric parameters (ply thickness. interphase thickness) have been simulated to quantify the scatter in the fit it matrix cracking strength (FMCS) and the ultimate tensile strength of SCS-6/RBSN (SiC fiber (SCS-6) reinforced reaction-honded silicon nitride composite) ceramic matrix composite laminate at room temperature. Cumulative probability distribution function for the FMCS and ultimate tensile strength at room temperature (RT) of $[0]_{8},\left[0_{2} / 90_{2}\right]_{\mathrm{S}}$, and $\left.\left[ \pm 45_{2}\right]_{\mathrm{S}}\right]$ aminates have been simulated and the sensitivity of primitive variables to the respective strengths have been quantified. Computationally predicted scatter of the strengths for a uniaxial laminate have been compared with those from limited experimental data. Also the experimental procedure used in the tests has been described briefly. Results show a very good agreement between the computational simulation and the experimental data. Dominating failure modes in $[0]_{8},[0 / 90]_{\mathrm{S}}$ and $[ \pm 45]_{\mathrm{S}}$ laminates have been identified. Results indicate that the first matrix cracking strength for the $[0]_{8}$, and $[0 / 90]_{\mathrm{S}}$ laminates is sensitive to the the mal properties, modulus and strengths of both the tiber and matrix whereas the ultimate tensile strength is sensitive to the fil ter strength and the fiber volume ratio. In the case of a $[ \pm 45]_{\mathrm{s}}$ laminate, both the FMCS and the ultimate tensile strengths have 1 small scatter range and are sensitive to the fiber tensile strength as well as the fiber volume ratio.

14. SUBJECT TERMS

Probability theory; Simulation; Probability density functions; Ceramic matrix composites; Sensitivity

17. SECURITY CLASSIFICATION OF REPORT

Unclassified
18. SECURITY CLASSIFICATION OF THIS PAGE Unclassified
19. SECUAITY CLASSIFICATION OF ABSTRACT

Unclassified 